\title{
Installation as a "Featured" Form of Art
}

\author{
Alexandra Orlova ${ }^{1, *}$ \\ ${ }^{1}$ State Institute for Art Studies, Moscow, Russia \\ *Corresponding author. Email: aocifra@ gmail.com

\begin{abstract}
Pieces created in the installation form of art demonstrate us the necessity of an immediate contact with works like these. That is why we need to have detailed descriptions of such pieces made by the eyewitness viewers. These descriptions help us to trace the installation's "life" because some of them may transform due to different factors as: adjustment to different exhibition spaces, curatorial conception and etc. The author will study these transformations and the way it affects the representation and interaction with the viewer on pieces produced by D. Prigov, T. Badanina, V. Korchagin, H. Sokol and other artists.
\end{abstract}

\section{Keywords: installation art, eye-witness viewer, perception, transformation, interaction}

\section{INTRODUCTION}

What does the brave new world of digital technologies give us? An ability to visit any museum without leaving our couch, or download an e-book instead of going to a local library. This process made our connection with the world of art and culture a lot easier in a way. But, in fact, there are still some forms of art that demand the viewer's presence, and installation art is one of them.

Due to its complex structure most of installations are hard to document by photo or video. It is connected with the participatory nature of some pieces or some site-specific aspects, e.g. the humidity and acoustics of the non-functioning hydroelectric generating station space. This, as Claire Bishop refers to it, "experiental" [1] and "open" [2] (Sergey Stupin's term) form of art creates a unique atmosphere that is supposed to be eyewitnessed by the viewers; and sometimes the same piece may transform a numerous amount of times due to the curatorial concept, space peculiarities, artist's decision, or any other circumstance. This way we may observe the installation's 'life' which will be the subject of this paper.

Being developed in the second half of the $20^{\text {th }}$ century installation art rapidly evolved from an experimental form of art that was commonly described as a "big art object" and associated with sculpture to an independent one. Today we cannot even imagine a contemporary art biennale that would not have an installation piece in it.

But when did the first installation piece appear? Some say that petroglyphic drawings with fire and some activity that ancient people had in the cave could be referred to as installation art, others say that Christian cathedrals with their complex interior system that develops another reality may remind of installations: "Historical precedents for Installation art can be traced at least as far back as painted triptychs in Renaissance churches as establishment of 'museums' in the West in the eighteenth century" [3]. From this we understand that installation-like features had always been present in multi-medium monumental of synthetic forms.

Russian artist Andrey Monastirsky once noted that: "...the artist who works with installation uses space as an instrument, but in fact creates something that is located in time, which appears to be an aesthetic (not only artistic) act" [4] that gives us an understanding that an installation art piece is a complex work that interacts with time and space simultaneously which means that the viewer's presence becomes important for the piece. This way we can make two categories of them - an eye-witness and a non-eye-witness. The first category name is easy to understand, but the second refers to those spectators who had no chance to be at the show but are familiar with the piece due to the fact that they have studied photo and video documentation about it. Another important matter about installation art is its performative nature. Just like a performance art piece installation exists in a particular moment, it has much less action than the performance, but, in fact, some performances now are identified as "live installations" due to the use of the montage aesthetics of installation art. 


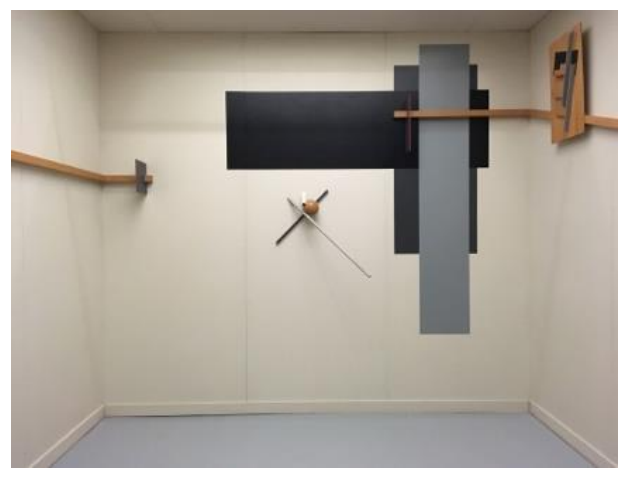

Fig. 1. E. Lissitzky "Proun Room". 1923. Picture made by A. Orlova at the Centre Pompidou in 2018.

Another important criteria that we should note about installation art is that pieces created in this form may transform their appearance during their so-called "life". These changes may occur due to the curatorial conception, artist's decision, special conditions and etc. E.g.: El Lissitzky's "Proun Room" (1923) ("Fig. 1") allowed spectators to rearrange objects in the piece, Kurt Schwitters's "Merzbau" (1937) was always growing in its size, Joseph Kosuth's "One and Three Chairs" (1965) and Nam June Paik's "TV Buddha" (1974) allow to use different inventory designs and etc. From these brief descriptions we comprehend that change is one of the most important installation art features.

Combining all these factors we see that installation art, unlike traditional forms of art, requires the presence of the viewer due to the temporal existence of the piece. But to understand more about installation artworks we need to find a proper definition of the term that will give us a full picture of what we understand installation art term is today.

\section{DEFINING INSTALLATION ART}

Previous paragraph gave us a slight conception of what to expect from an installation piece, but there are also some other features which require our attention as of an eye-witness during the interaction with such artwork. But it is important to have an up to date explanation of "installation art" term. Before we do that let's make it clear on what we understand under the "work of art" term. It is important because this understanding is a bit different in the contemporary art discourse.

For many of us it is quite obvious that if we see a sculpture or a painting that it is what we should name an art work. I doubt that somebody will have any hesitation on this problem. But when a non-professional viewer sees a piece of contemporary art that does not fill the criteria which was worked out during centuries (plausible view, beauty, understandable imagery), he or she may question if they are in the right place to be.
According to this problem an understanding came that: "One of the foremost problems of aesthetics has been to provide a definition (or an analysis, or an explication, or an elucidation) of the notion of a work of art" [5] — by this statement Paul Ziff raises an important for the $20^{\text {th }}$ century theory of art question.

After photography had been invented and Marcel Duchamp defunctionalized the role of the utilitarian object and demonstrated that it may transform into a piece of art, a lot of questions rose on what the work of art is today. To explain it Ziff offers an elegant model where he describes a dispute between new and old art critics, stressing up the fact that for the first ones it is important to use familiar categories, so the second ones would be able to understand them. Ziff offers an interesting solution for his time: "We must first know in what context we are to suppose the phrase "work of art' is being used." [6] - this way it allows us to separate the secular understanding of the term from the professional one. E.g. congressman George A. Dondero of Michigan, obviously the person with no art education, once wrote that: "Modern art is communistic because it is distorted and ugly ... Art which does not beautify our country in plain simple terms that everyone can understand breeds dissatisfaction" [7] — an erratic statement for today's situation, but you may be surprised how many people still support such archaistic point of view. For us it is important that: "... a certain type of work is considered a work of art, works of this type will eventually find their way into a public museum" [8]. That means that such pieces must be acknowledged by professional institutions as a "work of art". And since installation art has been recognized as an art form by the professional society we can move to the definition of what installation art is today.

Tate Guide to Modern Art Terms offers a more or less accurate explanation: "installation also described as environment, the term is used to describe mixed-media constructions or assemblages usually designed for a specific place and for a temporary period of time. Works often occupy an entire room or gallery space that the spectator invariably has to walk through in order to engage fully with the work of art. Some installations, however, are designed simply to be walked around and contemplated, or are so fragile that they can only be viewed from a doorway, or an end of a room" [9]. This explanation gives us some good points on what installation art is, but some of them are arguable. E.g.: in Russian terminology assemblage, environment and installation are three different forms of art. Assemblage is an attempt to escape the twodimensional world of a painting - a composition that is made from different objects, but has a frame, so it can be hanged on a wall. An assemblage can be included into an installation as a part of it. 
Unlike assemblage environment and installation stand separately. Of course, we remember that before the term "installation art" became well known many pieces were defined as "environments" by Russian art critics, which was not always a proper definition of these artworks. So, if an environment piece is an act of an artist interacting with nature, an installation art piece is something that you usually see in a gallery and is created from multiple parts (we will not focus on some outdoors installations in this paper).

Let's see what Russian philosopher Oleg Krivtsun can offer us as a definition: "Three-dimensional expressive construction which is made from specific materials or found objects and is intended to create a special emotional and sense atmosphere of a peculiar environmental effect...

First of all, installation art is a feeling capturing object" [10]. Here we come across a very important criteria which describes contemporary installations: atmosphere.

Atmosphere is the term of the new aesthetics which was described by Gernot Böhme in his text "Atmosphere as the Fundamental Concept of the New Aesthetics". In his paper, Böhme highlights that the term "atmosphere" was widely used in the philosophy of art discourse and seems to be one of the most important ones in contemporary aesthetics. He writes: "Atmosphere is the common reality of the perceiver and the perceived. It is the reality of the perceived as the sphere of its presence and the reality of the perceiver, insofar as in sensing the atmosphere it is bodily present in a certain way" [11]. This definition makes a lot of sense if you use it in the installation art context. In fact, we can say that the perception of a spectator who has interacted with the piece personally gains an "affected" [12] subjectivity because the eye-witness viewer had a contact not only with the piece itself, but also with the atmosphere the artist created in the space where the artwork had been installed and in some situations was a part of that piece. This why we move to a description that Elena Tavani gives to this art form: "With ... installations there is a full affirmation of the idea of the work-cum-environment, a work that envelops the viewer. Thus, we react to these installations as though reacting to an environment into which we enter" [13]. Due to this thesis we move to another important point that defines some contemporary installation - totality.

Total installation was described by Russian artist Ilya Kabakov, he pointed out that it is a piece that: "Total installation - installation built on the idea of including the viewer inside of it and aimed on the spectator's reaction in the closed, with no 'windows' space ..." [14].

We cannot state that all installations can be defined as total, but most of them strive to create such atmosphere. Another important point was highlighted by philosopher Boris Groys: "Installation transforms an empty, neutral public space into an individual art object and invites the visitor to perceive this space as an inner total space of a piece of art" [15], so totality of installation works may be obvious and may be hidden from the viewer, but still remains an important category.

Not only totality defines this form of art, sometimes we understand that installation art is site-specific: "Installation art is one of the most important and provocative developments in the visual arts during the last half century and has become a key focus of artists and of contemporary museums. It is also seen as particularly challenging or even disliked by many viewers, and-due to its unique in situ, immersive setting ..." [16] - a paper named "Capturing Aesthetic Experiences With Installation Art: An Empirical Assessment of Emotion, Evaluations, and Mobile Eye Tracking in Olafur Eliasson's 'Baroque, Baroque!" written by Matthew Pelowski, Helmut Leder, Vanessa Mitschke, Eva Specker, Gernot Gerger, Pablo P. L. Tinio, Elena Vaporova, Till Bieg and Agnes HussleinArco starts with these words. It reviews installation art from a psychological point of view, which gives us an interesting perspective and allows to take some material that gives an impact to our installation art definition. "Involving a monumental shift in emphasis from traditional bounded sculptures or two-dimensional images placed before a viewer, installation artworks are instead comprised of site-specific pieces that envelop an individual, often incorporating aspects of the existing environment and designed to bring about complex sensory and emotional experiences" [17] from this piece we see that the understanding of an installation art piece is based on the viewer's interaction with it and the site it was made for.

To conclude our study of this term's criteria let's finish with Boris Groys' statement which says that: "Installation, as any other art form, allows circulating human masses experience a right here, right now feeling" [18]. Having all this information we can make several bullet-points which will help us to explain what is important for an installation art piece:

- Mixed-media

- Creation of a specific atmosphere

- Totality

- Present spectators (eye-witnesses)

- Enveloping the viewer

- Possible change

- Open art form

- Simultaneous existence in space and time 
These are just some points that we will transform into a definition of the installation art term: Installation art is a synthetic mixed-media multi-object piece of art that may or may not occupy the whole exhibition space. Installation art may include: video, media, sound, objects, painting and any other medium that the artist may need to create a specific atmosphere with which the viewer will interact to gain an emotional experience. Due to the fact that installation is the socalled "open form of art" the viewer may become a part of it (the piece may envelope the viewer), so often his or her perception is affected. Detailed descriptions are important for the non-eye-witness viewers, who gain information about such pieces only through text, photo or video documentation that exist at the moment. The appearance of an installation piece may change numerous number of times, so there may be several different documentations of it.

\section{REASONS WHY AN INSTALLATION PIECE MAY CHANGE}

After we have defined what an installation art piece is, we can now move to some specifics that it has. It has been already mentioned that even in early installation examples there is some change in its appearance due to some conditions. The first one is that the artist him / herself implied this change into the piece. We have already mentioned it in the example of El Lissitzky's "Proun Room". Félix González-Torres created an "Untitled" piece in 1990, which is a $136 \mathrm{~kg}$ pile of individually wrapped candy. The viewers are offered to take and eat candy from the pile during the exhibit work, this way the artist stresses the ephemeral nature of art. So, change here is something that is implied into the work as a creative gesture.

Another example is Sergei Yakunin's piece "The Futuristic Printing Press" (2010), a participatory installation, it allows viewers to try themselves as Futurist movement printers from the beginning of the 20 th century. Not only the viewers become a part of an act of art, they may take their print with them, but prints that are left behind become a part of the piece.

When we interact with such pieces it is interesting to witness them as an "untouched" artwork and then look at them during the exhibit and in the very end of the show. This way we can see the dynamic of change. But when you see such a piece in the documentation it is quite tricky - it cannot give the non-eye-witness spectator an opportunity to feel the atmosphere of the artwork.

As we can see, some installations imply change in their conception. Now we may move to those that might not seem changeable, but actually are. It refers to some installations that do not have direct instructions on particular inventory details. We can understand it that the main agenda of the work is to give an impression, create a specific environment where the viewer is able to perceive the atmosphere. One of the examples that comes from the top of the head is Joseph Kosuth's famous piece "One and Three Chairs" which has already been mentioned above. This artwork demonstrates three phases of what we call "chair" - a picture of a chair, an actual chair and an explanation of the word "chair" copied from a dictionary. This way the artist plays with the so-called reality of this term. But, in fact, Kosuth does not require a specific chair at his shows, it may be any kind that fits the exhibit criteria - photo, real, term. This way we have a conceptual art product which gives the curators an instruction of how to blend the installation into the exhibition space, but its appearance may change constantly.

Dmitry Prigov's installations where he used newspapers and drew the eye of Omniscience are also a good example. When the artist was alive, he made the drawing himself, after he passed away, we can assume that the exhibitionists were recreating his installations using some photo footage. As for the newspapers, the artist always asked to bring black and white print. He was not interested in any particular news that might strike the spectator's attention and give him or her a feeling of a special connection with the artist.

These examples demonstrate that change of their appearance is not equal to the change of the conception of the work. That means that we cannot change the black and white printed newspapers to the colored ones because it will argue with the original idea of the piece. We can also note that installations like these may be categorized as "flexible" in this paper - they allow the curators use different designs of the inventory that will preserve the original conception. It is important to note because if a museum purchases an installation, sometimes it is not a physical object purchase, it is an idea purchase.

Another situation in which an installation piece may transform is the size of the exhibition space and its capability. In this section only the works of the now living artists will be described and the pieces that are their courtesy.

The first example will be Tatiana Badanina's installation "Sky. Requiem" (2015). The piece is dedicated to a touching story of how the artist's grandfather survived World War II. Badanina says that while creating the piece she copied her mother's experience who sewed in her own father's uniform notes with prayers before he went to war. The piece itself appears to be a set of paper shirts with symbolical prayers attached to them. In the ideal situation Badanina places these shirts on a huge wall and installs the light source behind each shirt. But in 2016, when she was attending the Russian State Art Library's exhibition named "Signs of Memories" the space did 
not allow to do the same trick. In order to save the conception of the piece only three shirts were displayed. Each of them was put into a tall glass case, where they were highlighted from the top. This decision was made to create an effect that each part of the installation is floating in the air. It is important to understand that in this case the curator asked for the artist's approval before making any move or decision. I assume that if this piece was in the collection of any institution and the collection curator had a strict instruction on how the installation must be displayed it would be impossible to introduce even a slight change into this artwork.

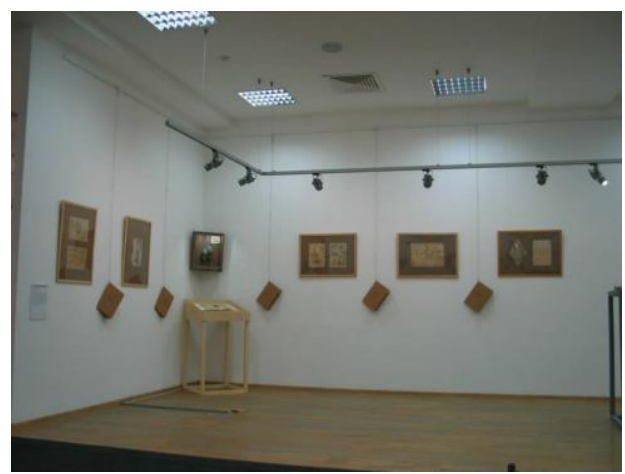

Fig. 2. V. Korchagin "Wool \& Potatoes". 2013. View on the installation. Picture taken by the artist in 2013.

The next example will also demonstrate how an installation art piece may transform in different exhibition spaces, but it will also show how the piece may change its appearance due to the exhibition conception. Valery Korchagin's work "Wool \& Potatoes" (2013) was made in the Artist Book genre and is a chamber piece. The piece is a mystification modified by the artist and the story behind it was: "A half rotten archive found at the old cottage attic gives an inside to Ivan Scotinin's (the owner the house) secret — his real identity" [19]. During the same year the work took part in a traveling exhibit named "Lower than Nizhny" ("Nizhe Nizhnego" in Rus.) ("Fig. 2"), where this small book transformed into not a huge but a medium scale installation which highlighted the important moments of the book.

Several years later in 2017 this piece became a part of Moscow Irish Week Festival's ("Fig. 3" and "Fig. 4") contemporary art program and was displayed as a total installation solo-show which enveloped any viewer and allowed them to have a glimpse into the story created by the artist. The solo-exhibition allowed Korchagin to produce additional objects, so the spectator would have an absolute feeling that he or she enters the house of the main character of this mystification - Ivan Scotinin.

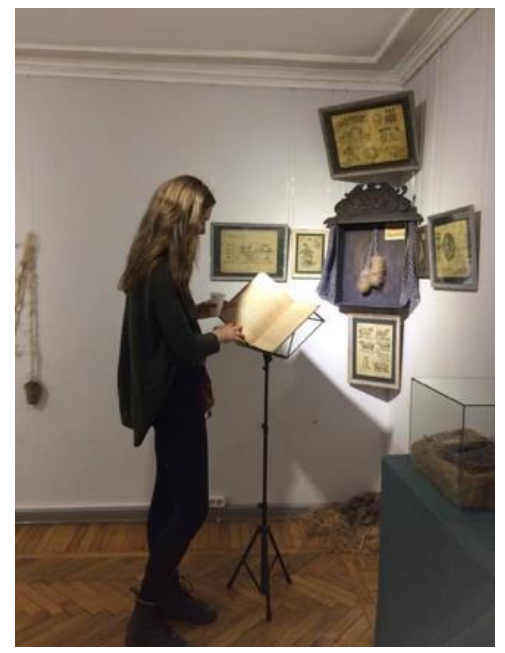

Fig. 3. V. Korchagin "Wool \& Potatoes". 2017. Fragment of the total installation. Picture taken by A. Orlova at Gnezdo gallery in 2017.

According to this example we can say that the artist himself was interested in the installation piece change because different approaches allowed to create specific environments for each situation.

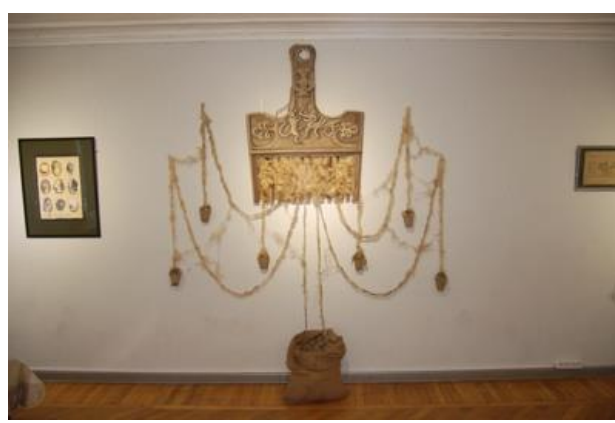

Fig. 4. V. Korchagin "Wool \& Potatoes". 2017. Fragment of the total installation. Picture taken by A. Orlova at Gnezdo gallery in 2017.

The last installation art change example will be the so-called pre-award exhibition. It is known that there are special prestigious awards in the world of contemporary art, in Russia this award is named Innovation, which is an annual ceremony. Before it an exhibition with all the nominees takes place. In order to demonstrate each of them most of the works are exhibited in a "cut" version.

Haim Sokol's piece "Spartacus. Times New Roman" (2014) was one of the nominees in "Innovation-2014". The curator of the show demonstrated the focal point of the whole installation - the arch which also played the important part in the video that Sokol planted into the piece - performance documentation where Asian migrant workers presented the War of Spartacus.

It is important to note that most of the people who came to the nominee exhibit were already familiar with 
the artwork. For them it was a reminder of their experience of the interaction with the total installation that Sokol displayed earlier in 2014. In this situation we see that such a digest-type show cannot give us a full picture, but it demonstrates recognizable visual references.

\section{CONCLUSION}

As we can see from this text - transformation is one of the important installation art features. It allows the viewers to get a complex understanding of one piece, depending in what context it is represented. And if in one exhibition an installation interacts and envelopes the viewer, in another one it may change into a detached artwork with another atmosphere. This phenomenon allows us to create multiple documentations for the on-eye-witnesses of such works that will allow them to compare and analyze them.

This change also implies the complex nature of the installation art form which "soaks" in almost every novelty in the world of art.

\section{References}

[1] C. Bishop, "Installation Art: A Critical History", London, Routledge, 2005, p. 6.

[2] S. Stupin, "The Phenomenon of the Open Form in Art of the 20th Century", Moscow, Indrik, 2012, 312 p.

[3] M. Rush, "New Media in Art", London, Thames \& Hudson, 2005, p. 124.

[4] A. Monastirsky, I. Makarevich's Lignomania in: "Igor Makarevich Lingomania", Moscow, XL Gallery, 1996, p. 6.

[5] P. Ziff, "The Task of Defining a Work of Art" in: "The Philosophical Review", vol. 62, no. 1 (Jan., 1953), p. 58.

[6] Ibid., p. 72.

[7] A.C. Danto, "The Abuse of Beauty" in: "Daedalus", vol. 131, no. 4, On Beauty (Fall, 2002), p. 37.

[8] P. Ziff, "The Task of Defining a Work of Art", p. 72.

[9] S. Wilson, J. Lack, "The Tate Guide to Modern Art Terms", London, Tate, 2008, 2012, p. 106.

[10] O. Krivtsun, "Basic Terms of Theory of Art. Encyclopaedical Dictionary", Moscow-Saint-Petersburg, Humanitarian Initiatives Center, 2018, p. 94

[11] G. Böhme, "Atmosphere as the Fundamental Concept of a New Aesthetics" in: "Thesis Eleven", vol. 36, issue 1, August 1, 1993, p. 122.

[12] S. Burkhanova-Khabadze, "The Epoch of an "Affested" Spectator: Garcés, Churchland" in: "Moscow Art Magazine", 2018, Issue 106, p. 54.

[13] E. Tavani, "The Construction of Situations and Atmospheres in Installation Art, Atmosphere" in: "Atmospheres. Testing a New Paradigm", Milano-Udine, Mimesis International, 2018, p. 130.

[14] I. Kabakov, "The Term Dictionary of Moscow Conceptual School", Moscow, Ad Marginem, 1999, p. 86.

[15] B. Groys, "Poetic Politics", Moscow, Ad Marginem Press, 2013, p. 65 .

[16] M. Pelowski, H. Leder, V. Mitschke, E. Specker, G. Gerger, P. L. Tinio Pablo, E. Vaporova, T. Bieg, A. Husslein-Arco,
"Capturing Aesthetic Experiences with Installation Art: An Empirical Assessment of Emotion, Evaluations, and Mobile Eye Tracking in Olafur Eliasson's "Baroque, Baroque!" in "Frontiers in Psycology", 6 August 2018, vol. 9, article 1255 URL:

https://www.frontiersin.org/articles/10.3389/fpsyg.2018.01255/f ull (access date: 29.06.2020).

[17] Ibid.

[18] B. Groys, "Poetic Politics", p. 73.

[19] V. Korchagin, "Wool \& Potatoes", Moscow, MystificArt, 2013, p. 64. 